\title{
Analisis Kesesuaian \\ Lokasi Pengembangan Ruang Terbuka Hijau Publik Di Kecamatan Palu Timur Dan Palu Barat
}

\author{
ANDI CHAIRUL ACHSAN1 \\ 1Program Studi Perencanaan Wilayah dan Kota, Fakultas Teknik, Universitas Tadulako \\ Kampus Bumi Tadulako Tondo JI. Soekaro Hatta Km. 9 Palu 94118, Indonesia \\ *Email: andichairulachsan@gmail.com
}

\begin{abstract}
Suitability Analysis of The Location of The Development Public Green Open Space in The Sub District Palu Timur and Palu Barat
\end{abstract}

The existence of green open spaces, especially for public green open spaces in the region of Palu City still showing lack of suitability with public aspect, therefore, to optimize the function of public space as a place for comfortable activities required the suitability analysis of the location to identify and determine prioritize the location of the development of public green open space based on aspects of the fulfillment of public functions. The purpose of this study was to identify and map the aspects that influence as well as analyze and determine the suitability of the location of the development of public green open space in the sub district of Palu Timur and Palu Barat. The results showed the suitability class of the location of development public green open space was divided into four class not suitable, enough suitable, suitable and very suitable.Based on the determination of suitability of location can be determined the priority of the location of the development of public green open space in the subdistrict Palu Timur and Palu Barat was located on an area with the suitability level very suitable with an area for subdistrict Palu Timur $885.576,32 \mathrm{~m}^{2}$ and Palu Barat 661.986,41 $\mathrm{m}^{2}$.

Keywords: suitability, location, green open space

\section{Pendahuluan}

\subsection{Latar Belakang}

Perkembangan kota di Indonesia sudah semakin pesat (Rushayati, dkk. 2011), berbagai macam upaya dilakukan untuk mewujudkan pengembangan kota yang optimal dan berkualitas, salah satu upaya yang dilakukan adalah menyediakan ruang terbuka hijau kota. Ketersediaan ruang terbuka hijau kota telah menjadi perhatian bagi setiap pemerintah daerah di Indonesia khususnya pada kota-kota besar sebagaimana tertuang dalam undang-undang penataan ruang no. 26 tahun 2007 yang mengamanatkan bahwa setiap kota harus memiliki luas ruang terbuka hijau sebesar $30 \%$ dari total luas wilayah 
kotanya. Ruang terbuka hijau memiliki beberapa manfaat penting bagi sebuah kota dan merupakan unsur alamiah maupun binaan yang sangat berperan dalam mewujudkan kota yang berwawasan lingkungan (Brahmantyo, dkk. 2012). Keberadaan ruang terbuka hijau kawasan perkotaan memiliki tujuan untuk menjaga keserasian dan keseimbangan ekosistem lingkungan perkotaan, mewujudkan keseimbangan antara lingkungan alam dan lingkungan buatan serta meningkatkan kualitas lingkungan perkotaan yang sehat, indah dan nyaman (Mukafi, 2013). Pembentukan sistem ruang terbuka hijau kota merupakan respon terhadap kebutuhan ruang terbuka hijau suatu wilayah perkotaan yang meliputi kebutuhan dari aspek ekologis, sosial, dan ekonomi wilayah tersebut (Rahmy, dkk. 2012).

Lokasi ruang terbuka hijau yang sesuai akan menentukan optimalnya penataan ruang terbuka hijau pada wilayah perkotaan. Perencanaan ruang terbuka hijau diupayakan dilakukan dengan mempertimbangkan distribusi atau lokasi ruang terbuka hijau (Laboratorium Perencanaan Lansekap, 2015). Lokasi ruang terbuka hijau khususnya ruang terbuka hijau publik hendaknya dapat disesuaikan keberadaannya dengan fungsi ruang kota khususnya yang berkaitan dengan fungsi-fungsi publik seperti permukiman, perdagangan dan penggunaan ruang publik lainnya agar aktivitas publik dapat berjalan secara baik serta ditunjang oleh lingkungan yang nyaman.

Keberadaan ruang terbuka hijau khususnya ruang terbuka hijau publik di diwilayah Kota Palu masih menunjukkan belum adanya kesesuaian yang optimal dengan hal-hal yang berkaitan dengan aspek publik seperti kaitannya dengan dengan aspek fungsi ruang atau penggunaan ruang kota khususnya ruang-ruang kota dengan aktivitas publik yang cukup tinggi seperti permukiman, perdagangan serta beberapa penggunaan ruang publik lainnya, aspek populasi penduduk, aksesibilitas, kerawanan terhadap masalah lingkungan serta beberapa aspek lainnya, oleh karena itu untuk mengoptimalkan fungsi ruang publik sebagai tempat untuk beraktivitas dan nyaman maka perlu dilakukan analisis kesesuaian lokasi untuk mengidentifikasi dan menentukan prioritas lokasi pengembangan ruang terbuka hijau publik yang didasarkarkan pada aspek-aspek pemenuhan fungsi publik (Miller, dkk. 1998).

Salah satu metode yang dapat digunakan untuk menganalisis kesesuaian lokasi untuk pengembangan ruang terbuka hijau adalah sistem informasi geografis. sistem informasi geografis adalah sistem informasi berbasis komputer yang digunakan untuk memasukkan dan memanipulasi informasi geografis (Aronoff, 1991, Barus, 2000). Sistem informasi geografis merupakan suatu sistem yang mengorganisir perangkat dan data, serta dapat mendayagunakan sistem penyimpanan, pengolahan, maupun analisis data secara simultan, sehingga dapat diperoleh informasi yang berkaitan dengan aspek keruangan atau spasial (Arsa, dkk. 2009).

\subsection{Tujuan Penelitian}

1. Mengidentifikasi dan memetakan aspek-aspek yang berpengaruh terhadap penentuan kesesuaian lokasi pengembangan ruang terbuka hijau publik di Kecamatan Palu Timur dan Palu Barat. 
2. Menganalisis dan menentukan kesesuaian lokasi pengembangan ruang terbuka hijau publik di Kecamatan Palu Timur dan Palu Barat menggunakan analisis sistem informasi geografis.

\section{Metode}

\subsection{Lokasi dan Waktu}

Penelitian dilakukan di wilayah Kecamatan Palu Timur dan Kecamatan Palu Barat, Kota Palu, Provinsi Sulawesi Tengah. Penelitian dilaksanakan selama 4 bulan dimulai sejak bulan Juli sampai dengan September 2015.

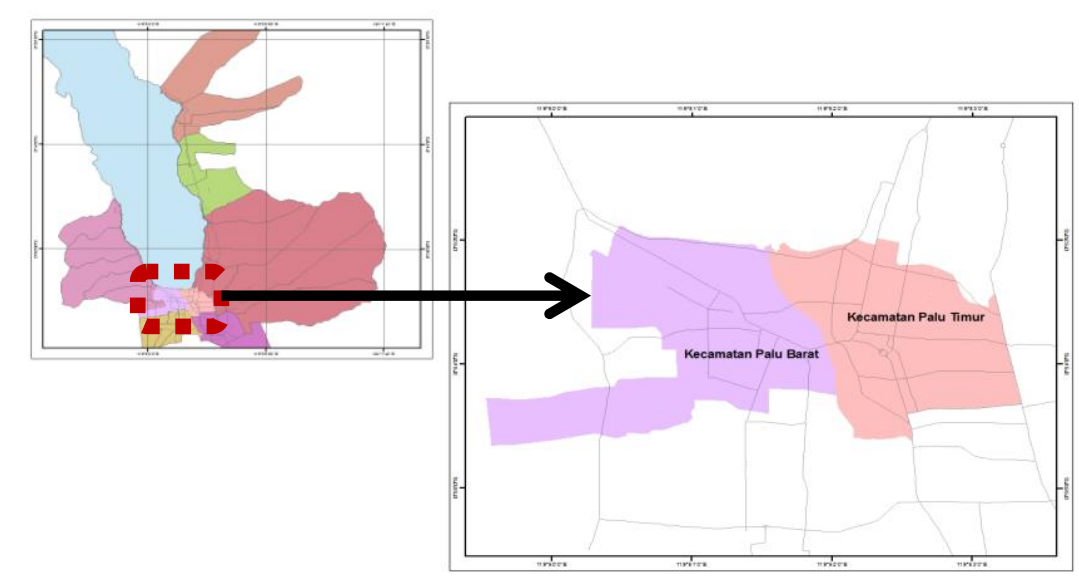

Gambar 1. Peta Lokasi Studi

\subsection{Alat dan Bahan}

Alat-alat yang digunakan dalam penelitian ini adalah seperangkat komputer, alat tulis dan perangkat lunak (software) untuk penyusunan naskah, pengolahan dan analisis data. Perangkat lunak yang digunakan terdiri dari Arc GIS 10, Microsoft Office dan Excell 2007. Bahan yang diperlukan untuk penelitian ini berupa, peta-peta yang terkait dengan aspek kependudukan, tata ruang, aksesibilitas dan sarana pendukung.

\subsection{Metode Penelitian}

Metode dalam penelitian ini meliputi pengumpulan data-data dan informasi yang diperlukan serta menganalisis data-data sesuai dengan kebutuhan dan tujuan studi.

\subsubsection{Teknik Pengumpulan Data Dan Jenis Data}

Jenis data yang diperlukan adalah data primer dan data sekunder . Data primer diperoleh dengan cara observasi ke lokasi atau obyek penelitian serta melakukan diskusi dan wawancara langsung dengan stakeholder. Data sekunder diperoleh dengan cara menelusuri berbagai sumber seperti hasil penelitian dan dokumen ilmiah dari instansi terkait. 


\subsubsection{Analisis Data}

Analisis Kesesuaian lokasi pengembangan ruang terbuka hijau publik Kecamatan Palu Timur dan Palu Barat meliputi analisis yang mencakup langkah-langkah sebagai berikut :

1. Identifikasi parameter dan kriteria

Langkah awal analisis kesesuaian lokasi adalah identifikasi data dasar atau parameter yang akan digunakan beserta kriteria untuk masing-masing parameter. Berdasarkan hasil identfikasi terhadap parameter yang dibutuhkan dalam melakukan analisis kesesuaian lokasi pengembangan ruang terbuka hijau ditentukan beberapa parameter yang dijadikan sebagai variabel pengukuran yang sesuai dengan kebutuhan analisis yang dilakukan, beberapa parameter tersebut dibagi kedalam beberapa kriteria diantaranya : kemiringan lereng, penggunaan lahan, kepadatan penduduk, aksesibilitas dan sarana pendukung.

2. Inventarisasi kebutuhan data

Setelah mengetahui parameter-parameter yang digunakan dalam proses analisis penentuan kesesuaian lokasi, langkah berikutnya adalah inventarisasi data-data yang merepresentasikan parameter tersebut.

3. Proses analisis sistem informasi geografis

Dari data yang ada kemudian diproses untuk dijadikan data yang dapat digunakan untuk menentukan lokasi yang sesuai bagi pengembangan ruang terbuka hijau publik. Analisis yang dimaksud menghasilkan peta yang terdiri dari : peta kelas kemiringan lereng, peta kelas penggunaan lahan, peta kelas kepadatan penduduk, peta kelas jarak terhadap jalan, peta kelas jarak terhadap pusat kota.

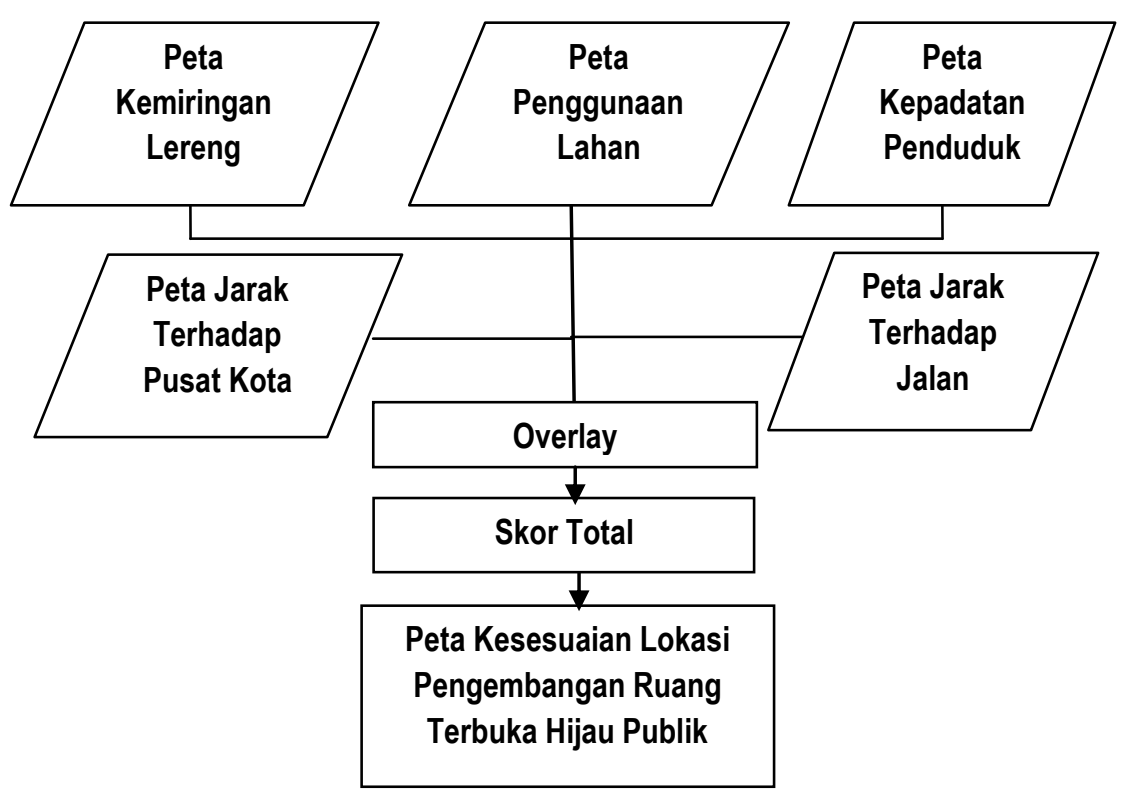

Gambar 2. Bagan Alur Penentuan Kesesuaian Lokasi Pengembangan Ruang Terbuka Hijau Publik di Kecamatan Palu Timur dan Palu Barat 
4. Penentuan kesesuaian lokasi pengembangan ruang terbuka hijau publik

Mekanisme penentuan kesesuaian lokasi pengembangan ruang terbuka hijau publik di Kecamatan Palu Timur dan Palu Barat dilakukan dengan cara skoring. Setiap kriteria yang digunakan (peta kelas kemiringan lereng, peta kelas kepadatan penduduk, peta kelas penggunaan lahan, peta jarak terhadap jalan dan peta jarak terhadap pusat kota) diklasifikasikan menjadi sub-sub kriteria dan dari masing masing sub kriteria ditentukan skor untuk masing-masing sub kriteria yang ada.

\section{Hasil Dan Pembahasan}

\subsection{Kriteria Kesesuaian Lokasi Pengembangan Ruang Terbuka Hijau Publik Kecamatan Palu Timur dan Palu Barat}

Kriteria penentuan kesesuaian lokasi pengembangan ruang terbuka hijau publik di Kecamatan Palu Timur dan Palu Barat dibagi kedalam 5 kriteria yaitu kemiringan lereng, penggunaan lahan, kepadatan penduduk, aksesibilitas dan sarana pendukung.

Kriteria kemiringan lereng dibagi kedalam tiga sub kriteria yaitu sub kriteria kemiringan lereng $0-8 \%$, sub kriteria kemiringan lereng 8-15\% dan sub kriteria kemiringan lereng $>15 \%$, kriteria penggunaan lahan dibagi kedalam empat sub kriteria yaitu sub kriteria kawasan ruang terbuka hijau, sub kriteria kawasan perdagangan, sub kriteria kawasan permukiman dan sub kriteria area penggunaan lain. Kriteria kepadatan penduduk dibagi kedalam tiga sub kriteria yaitu kawasan dengan kepadatan penduduk tinggi, kawasan dengan kepadatan penduduk sedang dan kawasan dengan kepadatan penduduk rendah. Kriteria aksesibilitas dibagi kedalam tiga sub kriteria yaitu jarak $200 \mathrm{~m}$ dari jalan arteri, jarak 400m dari jalan arteri dan jarak $>400 \mathrm{~m}$ dari jalan arteri. Kriteria sarana pendukung dibagi kedalam tiga sub kriteria yaitu jarak $500 \mathrm{~m}$ dari pusat kota, jarak $1000 \mathrm{~m}$ dari pusat kota dan jarak $>1000 \mathrm{~m}$ dari pusat kota.

\subsection{Skoring Parameter dan Pembuatan Peta Tematik}

Berdasarkan kriteria dan sub kriteria yang telah ditentukan diakukan skoring pada setiap sub kriteria. Skoring dilakukan untuk memberikan ukuran kesesuaian pada setiap sub kriteria dimana skor yang diberikan berada pada skala 1-3 (skor $3=$ kesesuaian tinggi, skor 2 = kesesuaian sedang, dan skor 1 = kesesuaian rendah).

Pada kriteria kemiringan lereng sub kriteria kemiringan lereng 0-8\% diberi skor 1 , sub kriteria kemiringan lereng $8-15 \%$ diberi skor 2 dan sub kriteria kemiringan lereng > $15 \%$ diberi skor 3 . Pada kriteria penggunaan lahan pada sub kriteria kawasan ruang terbuka hijau diberi skor 3, sub kriteria kawasan perdagangan diberi skor 3, sub kriteria kawasan permukiman diberi skor 3 dan sub kriteria area penggunaan lain di beri skor 1 . Pada kriteria kepadatan penduduk pada subkriteria kawasan kepadatan penduduk tinggi diberi skor 3, kawasan dengan kepadatan penduduk sedang dberi skor 2, kawasan dengan kepadatan penduduk rendah diberi skor 1. Pada kriteria akseseibilitas pada sub kriteria jarak $200 \mathrm{~m}$ dari jalan arteri diberi skor 3, jarak $400 \mathrm{~m}$ dari jalan arteri diberi skor 2dan jarak $>400 \mathrm{~m}$ dari jalan arteri diberi skor 1 . Pada kriteria sarana pendukung pada 
sub kriteria jarak $500 \mathrm{~m}$ dari pusat kota diberi skor 3, jarak $1000 \mathrm{~m}$ dari pusat kota diberi skor 2 dan jarak $>1000 \mathrm{~m}$ dari pusat kota diberi skor 1 .

Berdasarkan skoring yang dilakukan pada setiap kriteria selanjutnya dilakukan pembuatan peta tematik yaitu peta klasifikasi atau kelas kriteria pada masing-masing kriteria sesuai dengan sub kriteria yang telah ditentukan dan telah dilakukan skoring.

Tabel 1. Skoring Kriteria Penentuan Lokasi Pengembangan Ruang Terbuka Hijau Publik di Kecamatan Palu Timur dan Palu Barat

\begin{tabular}{lllc}
\hline \multicolumn{1}{c}{ Parameter } & \multicolumn{1}{c}{ Kriteria } & \multicolumn{1}{c}{ Sub Kriteria } & Skor \\
\hline Kemiringan & Tingkat & Kemiringan Lereng 0-8\% & 1 \\
Lereng & Kemiringan & Kemiringan Lereng 8-15\% & 2 \\
& Lereng & Kemiringan Lereng > 15\% & 3 \\
Penggunaan & Kelas & Ruang Terbuka Hijau & 3 \\
Lahan & Penggunaan & Perdagangan & 3 \\
& Lahan & Permukiman & 3 \\
& & Areal Penggunaan Lain & 1 \\
Kepadatan & Tingkat & Kep. Penduduk Tinggi (200-400 jiwa/ha) & 3 \\
Penduduk & Kepadatan & Kep. Penduduk Sedang (151-200 jiwa/ha) & 2 \\
& & Kep. Penduduk Rendah (<150 jiwa/ha) & 1 \\
Aksesibilitas & Jarak & Jarak 200 m dari Jalan Arteri & 3 \\
& Terhadap Jalan & Jarak 400 m dari Jalan Arteri & 2 \\
& Arteri & Jarak $>400$ m dari Jalan Arteri & 1 \\
Sarana & Jarak Dari & Jarak 500 m dari Pusat Kota & 3 \\
Pendukung & Pusat Kota & Jarak 1000 m dari Pusat Kota & 2 \\
& & Jarak $>1000$ m dari Pusat Kota & 1 \\
\hline
\end{tabular}
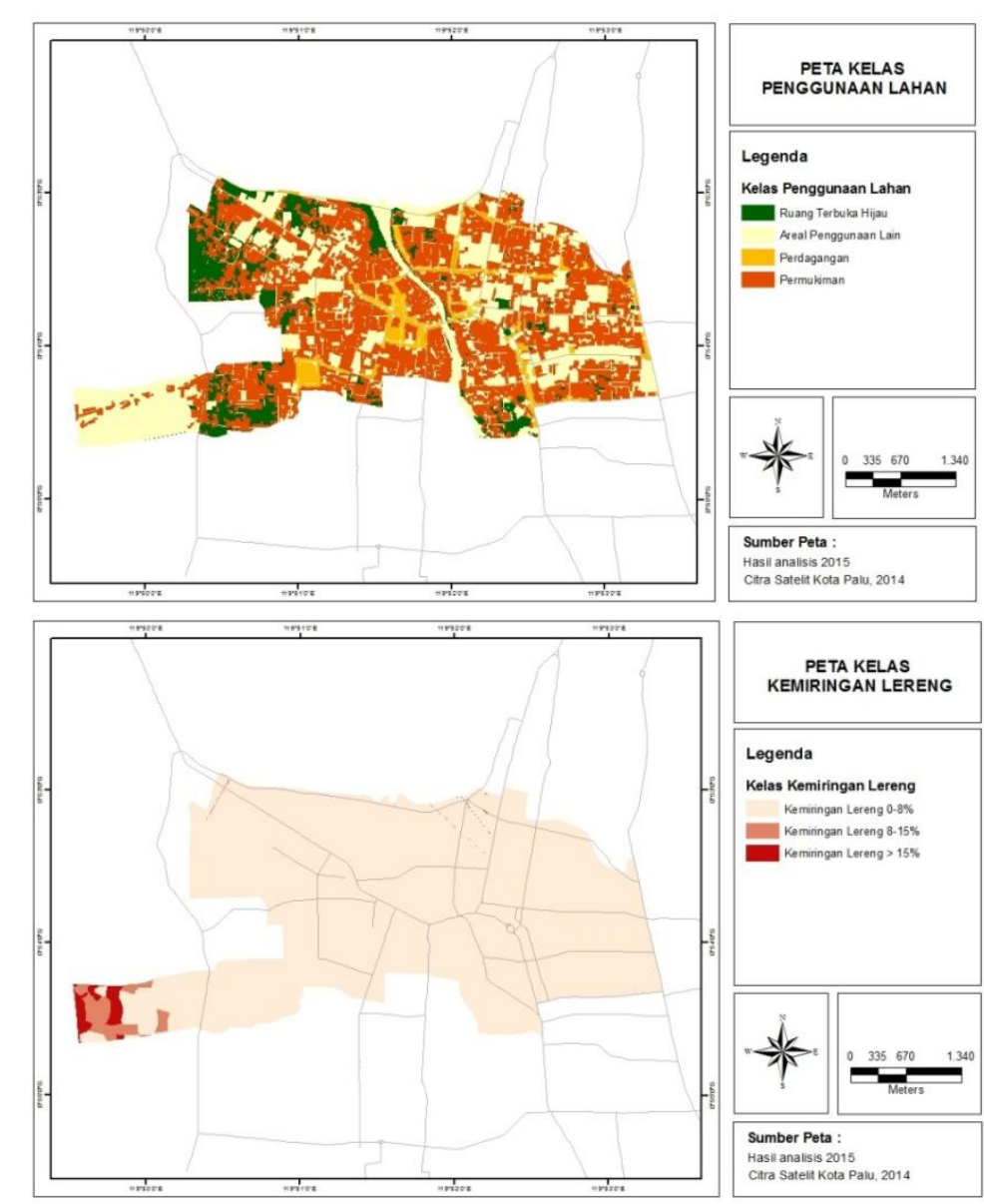

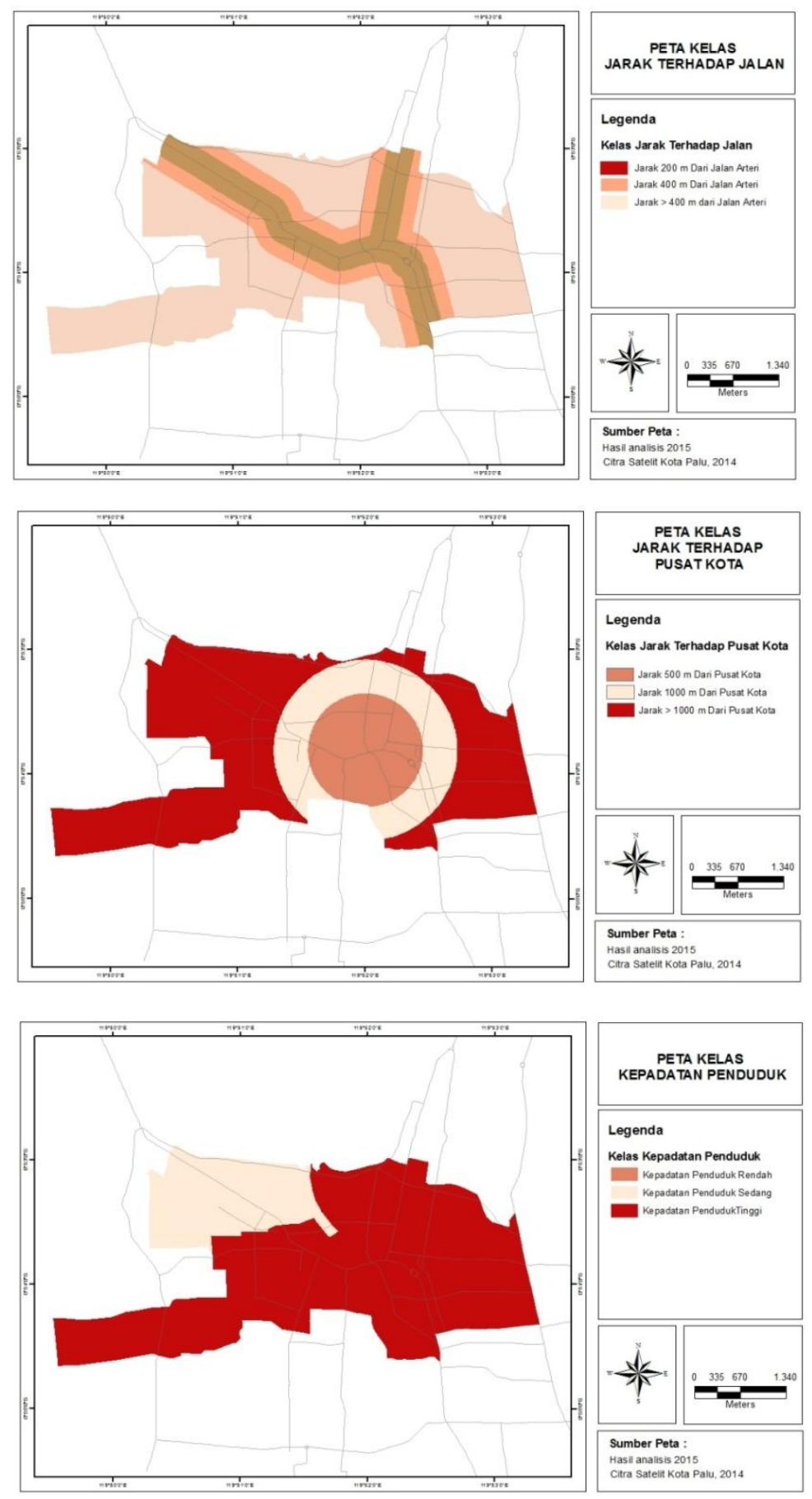

Gambar 3. Peta Tematik Kriteria Pengembangan Ruang Terbuka Hijau Publik di Kecamatan Palu Timur dan Palu Barat (Peta Kelas Kemiringan Lereng, Penggunaan Lahan, Kepadatan Penduduk, Jarak terhadap Jalan dan Jarak Terhadap Pusat Kota)

\subsection{Penentuan Kesesuaian Lokasi Pengembangan Ruang Terbuka Hijau Publik Kecamatan Palu Timur dan Palu Barat}

Berdasarkan peta-peta tematik yang telah disusun, proses penentuan kesesuaian lokasi pengembangan ruang terbuka hijau publik di Kecamatan Palu Timur dan Palu Barat dilakukan dengan melakukan overlay atau tumpang susun atas peta-peta tematik yang 
telah dibuat. Pada proses overlay dilakukan penjumlahan skor dari setiap skor yang ada pada setiap peta kelas kriteria.

Hasil penjumlahan yang diperoleh menunjukkan nilai tertinggi hingga terendah, nilai yang diperoleh tersebut diklasifikasi menjadi 4 kelas yaitu kelas kesesuaian lokasi dengan kriteria sangat sesuai, sesuai, cukup sesuai, dan kelas lokasi tidak sesuai. Kelas lokasi dengan kriteria sangat sesuai menunjukkan nilai dengan tingkat kesesuaian yang tinggi untuk pengembangan ruang terbuka hijau publik sedangkan kelas lokasi tidak sesuai menunjukkan nilai tingkat kesesuaian rendah untuk pengembangan ruang terbuka hijau publik.

Berdasarkan hasil penentuan zonasi kesesuaian lokasi pengembangan ruang terbuka hijau publik Kecamatan Palu Timur dan Palu Barat diperoleh informasi luas area untuk setiap kelas kesesuaian lokasi pada dua wilayah kecamatan dimana untuk kelas kesesuaian tidak sesuai memiliki luas $12.176,56 \mathrm{~m}^{2}$, cukup sesuai memiliki luas 4.351.221,80 $\mathrm{m}^{2}$, sesuai memiliki luas 7.493.811,62 $\mathrm{m}^{2}$, dan sangat sesuai 1.547.562,74 $\mathrm{m}^{2}$ sedangkan berdasarkan setiap wilayah kecamatan, untuk wilayah Kecamatan Palu Timur untuk kelas kesesuaian tidak sesuai memiliki luas 11.184,96 $\mathrm{m}^{2}$, cukup sesuai memiliki luas 1.343.845,19 $\mathrm{m}^{2}$, sesuai memiliki luas $3.774 .318,32 \mathrm{~m}^{2}$, dan sangat sesuai 885.576,32 $\mathrm{m}^{2}$ dan untuk wilayah Kecamatan Palu Barat untuk kelas kesesuaian tidak sesuai memiliki luas $991,60 \mathrm{~m}^{2}$, cukup sesuai memiliki luas $3.007 .376,61 \mathrm{~m}^{2}$, sesuai memiliki luas $3.719 .493,31 \mathrm{~m}^{2}$, dan sangat sesuai $661.986,41 \mathrm{~m}^{2}$.

Tabel 2. Luas Area Kesesuaian Lokasi Pengembangan Ruang Terbuka Hijau Publik di Dua Wilayah Kecamatan

\begin{tabular}{ll}
\hline \multicolumn{1}{c}{ Kelas Kesesuaian Lokasi } & \multicolumn{1}{c}{ Luas Area $\left(\mathbf{m}^{2}\right)$} \\
\hline Tidak Sesuai & $12.176,56$ \\
Cukup Sesuai & $4.351 .221,80$ \\
Sesuai & $7.493 .811,62$ \\
Sangat Sesuai & $1.547 .562,74$ \\
\hline
\end{tabular}

Tabel 3. Luas Area Kesesuaian Lokasi Pengembangan Ruang Terbuka Hijau Publik di Tiap Wilayah Kecamatan

\begin{tabular}{ccc}
\hline \multirow{2}{*}{ Kelas Kesesuaian Lokasi } & \multicolumn{2}{c}{ Luas Per Kecamatan } \\
& Kecamatan Palu Timur & Kecamatan Palu Barat \\
\hline Tidak Sesuai & $11.184,96$ & 991,60 \\
Cukup Sesuai & $1.343 .845,19$ & $3.007 .376,61$ \\
Sesuai & $3.774 .318,32$ & $3.719 .493,31$ \\
Sangat Sesuai & $885.576,32$ & $661.986,41$ \\
\hline
\end{tabular}

Berdasarkan hasil penentuan kesesuaian lokasi maka dapat ditentukan prioritas lokasi pengembangan ruang terbuka hijau publik di Kecamatan Palu Timur dan Palu Barat adalah pada area dengan tingkat kesesuaian sangat sesuai dengan luas area masing- 
masing untuk wilayah Kecamatan Palu Timur memiliki luas 885.576,32 $\mathrm{m}^{2}$ dan Kecamatan Palu Barat memiliki luas $661.986,41 \mathrm{~m}^{2}$.

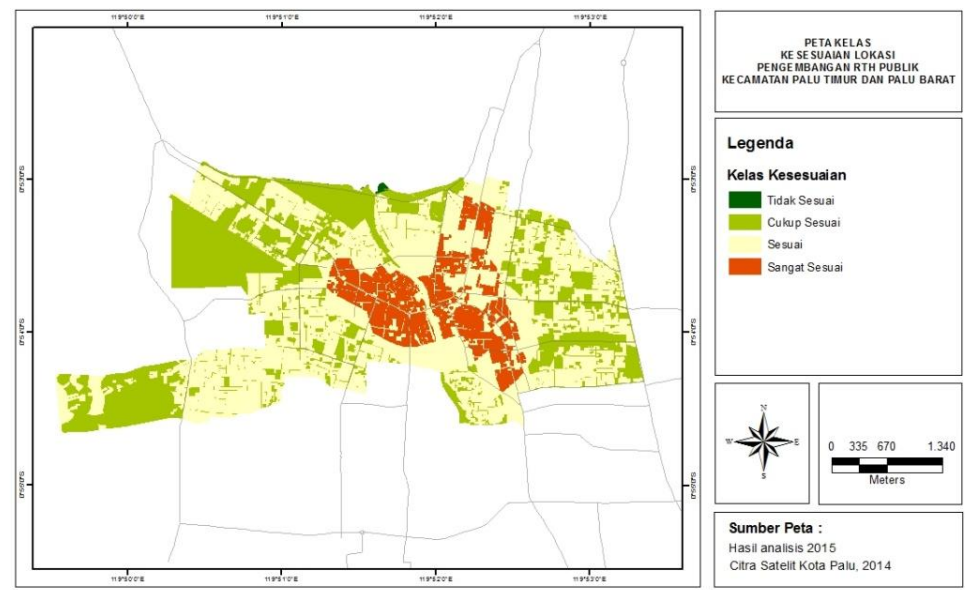

Gambar 4. Peta Kesesuaian Lokasi Pengembangan Ruang Terbuka Hijau Publik di Kecamatan Palu Timur Dan Palu Barat

\section{Simpulan}

1. Penentuan kesesuaian lokasi pengembangan ruang terbuka hijau publik pada Kecamatan Palu Timur dan Palu Barat didasarkan pada aspek kemiringan lereng penggunaan lahan, kepadatan penduduk, aksesibilitas dan sarana pendukung.

2. Zonasi kesesuaian lokasi pengembangan ruang terbuka hijau publik Kecamatan Palu Timur dan Palu Barat dibagi kedalam 4 kelas zona yaitu untuk kelas kesesuaian tidak sesuai memiliki luas $12.176,56 \mathrm{~m}^{2}$, cukup sesuai memiliki luas $4.351 .221,80 \mathrm{~m}^{2}$, sesuai memiliki luas $7.493 .811,62 \mathrm{~m}^{2}$, dan sangat sesuai $1.547 .562,74 \mathrm{~m}^{2}$.

3. Kesesuaian lokasi berdasarkan wilayah kecamatan, untuk wilayah Kecamatan Palu Timur untuk kelas kesesuaian tidak sesuai memiliki luas $11.184,96 \mathrm{~m}^{2}$, cukup sesuai memiliki luas $1.343 .845,19 \mathrm{~m}^{2}$, sesuai memiliki luas $3.774 .318,32 \mathrm{~m}^{2}$, dan sangat sesuai $885.576,32 \mathrm{~m}^{2}$ dan untuk wilayah Kecamatan Palu Barat untuk kelas kesesuaian tidak sesuai memiliki luas $991,60 \mathrm{~m}^{2}$, cukup sesuai memiliki luas $3.007 .376,61 \mathrm{~m}^{2}$, sesuai memiliki luas $3.719 .493,31 \mathrm{~m}^{2}$, dan sangat sesuai $661.986,41 \mathrm{~m}^{2}$.

4. Prioritas lokasi pengembangan ruang terbuka hijau publik di Kecamatan Palu Timur dan Palu Barat adalah pada area dengan tingkat kesesuaian sangat sesuai dengan luas area masing-masing untuk wilayah Kecamatan Palu Timur memiliki luas 885.576,32 $\mathrm{m}^{2}$ dan Kecamatan Palu Barat memiliki luas 661.986,41 m².

\section{Daftar Pustaka}

Aronoff, S. 1991. Geographic Information System : A Management Perspective. Ottawa : WDL Publications. 294p. 
Arsa, H. Hariyanto, T. 2009. Pemetaan Dan Penyusunan Basisdata Ruang Terbuka Hijau Kota Dengan Menggunakan Sistem Informasi Geografis (Studi Kasus Kota Surabaya) Jurusan Teknik Geomatika, Fakultas Teknik Sipil dan Perencanaan, Institut Teknologi Sepuluh Nopember

Barus, B. Wiradisastra, U.S. 2000. Sistem Informasi Geografi Sarana Manajemen Sumberdaya. Laboratorium Penginderaan Jauh dan Kartografi, Jurusan Tanah, Fakultas Pertanian, Institut Pertanian Bogor.

Brahmantyo, T. Kustiwan, I. 2012. Evaluasi Penyediaan Ruang Terbuka Hijau Sebagai Infrastruktur Hijau di Kota Bogor dan Cirebon. Jurnal Perencanaan Wilayah dan Kota, 1(2) 2:54-60.

Laboratorium Perencanaan Lansekap. 2015. Ruang Terbuka Hijau Wilayah Perkotaan, Makalah Lokakarya Pengembangan Sistem Ruang Terbuka Hijau Di Perkotaan Dalam Rangkaian Acara Hari Bakti Pekerjaan Umum Ke 60 Direktorat Jenderal Penataan Ruang Departemen Pekerjaan Umum.

Miller, W. Collins, M.G. Steiner, F.R. Cook, E. 1998. An Approach Greenway Suitability Analysis. Elsevier. Landscape and Urban Planning. 42. 91-105.

Mukafi, A. 2013. Tingkat Ketersediaan Ruang Terbuka Hijau Publik Di Kota Kudus. Skripsi. Universitas Negeri Semarang.

Peraturan Menteri pekerjaan Umum Nomor : 05/PRT/M/2008 tentang Pedoman Penyediaan dan Pemanfaatan Ruang Terbuka Hijau di Kawasan Perkotaan.

Rahmy, W.A. Faisal, B. Soeriaatmaja, A.R. 2012. Kebutuhan Ruang Terbuka Hijau Pada

Kawasan Padat Penduduk Studi Kasus Wilayah Tegallega Bandung. Jurnal Lingkungan Binaan Indonesia, 1(1):28-38.

Rushayati, S.B. Aikodra, H.S. Dahlan, E.N. Purnomo H. 2011. Pengembangan Ruang Terbuka Hijau Berdasarkan Distribusi Suhu Permukaan Di Kabupaten Bandung. Forum Geografi, 1(25):17-26.

Undang-undang Penataan Ruang Nomor 26 Tahun 2007. 